\title{
The Task Facing Educational Reformers: Making the Transition from Individual Intelligence to Ecological Intelligence
}

\author{
C. A. (Chet) Bowers \\ University of Oregon
}

\section{Invited Keynote Presentation}

The problem today is that most of us have been educated in western style educational institutions and thus have been socialized to think and communicate in the metaphorical language framed by analogs settled upon by earlier western thinkers who were unaware of environmental limits. The combination of hubris and a deeply held prejudice toward indigenous cultures that had already developed ecological intelligence that enabled many of them to live within the limits and possibilities of their bioregion led western thinkers to take a different path into the future.

As we can now recognize, this path has led to environmentally destructive technologies and the hyper-consumer dependent lifestyle that is now being globalized. Whether we have the time to develop a life-sustaining ecological intelligence will depend upon the length of time we have before the rate and scale of environmental changes embroil all Americans in the struggle for survival that will go beyond the current efforts to maintain a debt-dependent standard of living. It will also depend upon whether public school teachers and university professors have the will to recognize how the past continues the linguistic colonization of the present. Unfortunately, even if our educational institutions are able to socialize the next generations in how to exercise ecological intelligence in their daily lives, political power will remain in the hands of the older generations that were socialized to the industrial/capitalist mode of consciousness. Even in the face of mounting evidence that the environmental crisis is not a scare tactic of liberals, a large and powerful segment of the American population still place profits and the exploitation of the environment and other people (especially low wage workers in other cultures) above all other considerations. If we are to take Albert Einstein's warning seriously, namely that we cannot rely upon the same mind-set that created the problem to fix it, we need to begin thinking of how to exercise ecological intelligence and thus to move to a post-industrial form of consciousness. This will be an especially difficult challenge for classroom teachers and university professors who have be socialized to think in the metaphorical language that earlier thinkers succeeded in establishing as the basis of modern thought.

Before discussing some of the characteristics of ecological intelligence that will represent a special challenge for western thinkers, it is necessary to identify the scale and scope of the ecological crises-especially since our technologies and economic systems are able to maintain the illusion for many people that this is still an era of plenitude and that, if there is a problem, it is that they do not 
have enough money to consume as much as can be produce. There are many dimensions of the ecological crises that are beginning to impact directly the lives of the middle class in many countries, and are already threatening the lives of several billions of people who are struggling to meet the basic necessities of life. These include the melting of glaciers that are the source of potable water, the spread of droughts, the changes in the chemistry of the world's oceans and the collapse of major fisheries, the disappearance of over thirty percent of the world's topsoil, the loss of forests that serve as carbon sinks, and the extinction of species. Other losses that usually do not make this kind of list include the loss of linguistic diversity and the loss of the intergenerational knowledge that sustain the diversity of the world's cultural commons. The latter two losses are especially important as they are sources of knowledge and skills that have enabled different cultures to live with a smaller carbon and toxic footprint. Today, these losses force more people to being dependent upon consumerism at a time when automation, outsourcing and downsizing by corporations in search of greater profits make it increasingly difficult to earn the money necessary for meeting basic needs. As the word "ecology," especially among scientists, has become as widely used as the word "sustainability," it is necessary to identify how it reframes the meaning of "intelligence". Daniel Goleman's new book, Ecological Intelligence (2009), will likely popularize the phrase among the general population. But his book is unlikely to lead to the realization that ecological intelligence requires a radical shift in thinking. Goleman starts off by recognizing that ecologies are complex interacting natural systems that sustain life-including how the future of humans is dependent upon understanding how their behavior impacts the self-renewing capacity of these systems. Unfortunately, he promotes a narrow and basically misleading understanding of ecological intelligence. By reducing it to basing consumer decisions on knowing the Life Cycle Assessment of various products (i.e., the history of the production process-including the use of toxic materials) any hints that ecological intelligence will require rethinking the widely held view of intelligence as an individual attribute are overwhelmed by his association of ecological intelligence with being a more informed consumer. One of the unfortunate consequences of his book is that many people will begin to think of ecological intelligence as a matter of obtaining information from websites such as the Berkeley based GoodGuide that alerts consumers about the ecological impacts of different products. This criticism is not to denigrate the importance of learning about the toxic consequences of different products on various natural systems, but it needs to alert us to the need for a deeper understanding of the nature of ecological intelligence - as well as the modern ways of thinking that undermine it.

The three interconnected areas we need to rethink if educational reforms are to contribute to making the transition to an ecological form of intelligence include the following. First, we need to learn to make the transition from thinking of intelligence as an attribute of the autonomous individual to understanding the characteristics of ecological intelligence, as well as how to reinforce them as part of the student's taken-for-granted pattern of thinking. Second, there needs to be wider understanding on the part of educators of how language carries forward the misconceptions and values of earlier thinkers who were unaware of environmental limits. Third, how to revitalize the cultural commons, as well as 
understanding how they are being undermined, need to become part of the curricula of public schools and universities. At the university level, the focus needs to be on the various cultural forces that are transforming what remains of the world's diversity of cultural commons into new markets. These forces include the destructive influence of western philosophers and social theorists who ignored environmental limits as well as other cultural ways of knowing. How ideologies and religions that justify cultural colonization, technologies such as computers that marginalize awareness of the importance of contexts and intergenerational knowledge of how to live less consumer dependent lives, various status systems, and the educational sources of cultural amnesia and marginalization also need to be the focus of a university education.

In the interest of brevity, I will summarize key ideas in three areas that must be addressed in thinking about educational reforms that foster ecological intelligence. My focus will be on the ecologically problematic cultural assumptions and linguistic patterns that are taken-for-granted by most classroom teachers and university professors, and not on the daunting challenge of how to get them to rethink the assumptions their academic careers are based upon. Fostering ecological intelligence: The ancient Greek word oikos referred to a wide range of cultural practices in the household and community. It was only later that Ernst Haeckel (1834-1919) transformed it into the neologism "oecologie" that eventually became "ecology"- that is, the study of natural systems. We need to recover the ancient Greek understanding of learning the cultural patterns of moral reciprocity essential to community-while also retaining the more contemporary understanding of the behavior of natural systems as ecologies. Both cultural and natural ecologies involve interdependent systems, where no organism or action exists on its own. Gregory Bateson refers to the changes circulating within different ecosystems, and within and between cultural and natural systems as the "difference which makes a difference" (1972, p. 315). These differences, or actions upon an action, can also be understood as the patterns that connect, which in turn lead to changes in other parts of the cultural and natural ecology. In short, ecological intelligence takes account of relationships, contexts as well as the impacts of ideas and behaviors on other members in the cultural and natural systems. Rachel Carson's recognition of the connections between the use of DDT and the decline in the local population of birds is an example of recognizing the patterns that connect. Many of her critics took-for-granted, that like other scientific discoveries, DDT was yet another expression of progress - which led them to ignore the impact on natural systems. The myth of progress, especially scientific-based progress, reinforced the takenfor-granted pattern of thinking that, in turn, led to ignoring the difference (introduction of a toxic pesticide) that makes a difference (the dying off of birds).

Ecological intelligence is what many indigenous cultures rely upon in order to adapt their cultural practices to the cycles of renewal in their bioregions. For example, the Quechua of the Peruvian Andes express ecological intelligence in their ability to observe what the changes in their environment are communicating about when and where they should plant their fields. Their ceremonies both reenact the patterns of human/nature interdependence as well as give thanks for how nature nurtures them. Ecologically-oriented scientists are now exercising a limited form of ecological intelligence as they study the energy flows and cycles 
of renewal. Social scientists also rely upon a limited form of ecological intelligence when they study the patterns that connect, such as how the patterns of discrimination and class differences impact the lives of people.

Ecological intelligence takes into account the interacting patterns, ranging from how behaviors ripple through the field of social relationships in ways that introduce changes that are ignored by non-ecological thinking, to how an individual's actions introduce changes in the energy flows and alter the patterns of interdependence within natural systems. When we pay attention to contexts, interactions, and the consequences that follow from these actions, we are also exercising ecological intelligence. Ecological intelligence is not something we have to create anew as it goes back to the form of intelligence exercised in hunter-gather cultures. They had their mythopoetic narratives, but their survival depended upon careful observation of the cycles and patterns in the environment - as well as the intergenerational knowledge they continually tested and refined.

Unfortunately, western philosophers from Plato to the present have largely denigrated this form of intelligence by representing rational, abstract and thus decontextualized thinking as having higher status (Bowers 2008). Over the centuries, ecological intelligence has been further undermined as the idea of the autonomous individual became accepted as the basis of our political and social justice system - and now as the source of ideas and values. The introduction of perspective by artists in the early $15^{\text {th }}$ century helped to strengthen the cultural myth that privileged the individual as a separate onlooker on an external world, just as Rene Descartes further strengthened the myth of intelligence as separate from the cultural and natural ecologies that individuals interact with in ways that are too often ignored. Today, the myth of the autonomous individual is being reinforced by educators who urge students to construct their own ideas, and who promote computer-mediated learning on the grounds that it enables students to decide what they want to learn and value. Cell phones as well as many other cultural forces further undermine awareness of contexts, relationships, interdependencies, and the consequences of human behaviors that ripple through both cultural and environmental ecologies. Such taken-for-granted linguistic conventions as using the phrases "I think," "I want," and "what do you think?" continually reinforce the myth of not being part of the interdependent cultural and natural ecosystems, but rather being a separate observer, thinker, and actor. What are the implications for educational reformers? The first would be to become more aware of how the taken-for-granted cultural assumptions influence whether intelligence is interpreted as the attribute of an autonomous individual. Special attention needs to be given to how the student may represent her/himself as being an autonomous observer, and source of originality and intentionality. As noted above, this assumption as well as many of today's other taken-for-granted cultural assumptions gave conceptual direction and moral legitimacy to the industrial/consumer culture that is now entering its digital phase of globalization. Other assumptions include the idea that change is an inherently progressive force, that this is a human-centered universe, that mechanism provides the best explanatory framework for understanding organic processes, that language is a conduit in a sender/receiver process of communication, that traditions limit the individual's freedom and self-discovery, that (still for some) patriarchy was part 
of the original creative process, and that free markets have the same standing as the law of gravity. A second suggestion would be for participants in a learning situation to reinforce each other in giving greater attention to the cultural and environmental patterns that connect, to the consequences that follow from different behaviors, and to consider whether these consequences have an empowering or detrimental effect on others - in both the cultural and natural systems. The subjectively-centered self is such a prominent tradition in mainstream western culture, even among artists and people searching for a deeper sense of meaning and purpose, that it needs to be discussed and, if possible, reframed in ways that take account of how an action affects the actions of others, including the natural systems, in ways that influence their development. A key to making the transition to ecological intelligence is recognizing that there are no isolated events, facts, actions-everything, as Bateson points out, is part of a larger system of information exchanges. One of the more difficult sources of resistance to obtaining this awareness is the way in which print, both in books and in computer-mediated communication and thinking, marginalizes the importance of contexts, tacit understandings, and awareness of the history of the larger network of relationships. Even when what is represented by the printed word is situated in terms of its history, the history is also an abstract construction that is unable to accurately represent the culturally mediated embodied experiences of participating in the cultural and natural ecology of an earlier time. How language thinks us as we think within the possibilities made available by the language: Just as the cultural assumptions have led to thinking that individuals are basically autonomous beings (or have the potential to become autonomous), we have a tradition of thinking of the other participants in these complex cultural and natural ecologies as being selfcontained entities, such as a weed, a crime, a behavior, a value, an idea, and even the printed word. The spoken word, on the other hand, makes it easier to recognize the different dimensions of the cultural ecology in which it occurs. Context, memory, reciprocal actions, tacit understandings, and immediate consequences are accessed through all the senses, and effect understandings and actions. Given the privileged status that the printed word has in public schools and universities, it is necessary to emphasize the importance of helping students to recognize that words are not autonomous entities into which teachers/professors, authors, and computer software writers put their meanings and then convey them to others.

Our educational institutions leave most graduates with the idea that language is a neutral conduit that enables ideas, objective data, and information to be passed to others. That is, most students graduate without understanding that most words are metaphors that carry forward the meanings framed by an earlier choice of analogs. Many of these analogs were chosen by men who were unaware of environmental limits, and who took for granted many of the cultural assumptions of their era.

Recognizing that words have a history has important implications that are seldom considered. That is, they are part of a complex linguistic ecology that can be traced back to earlier narratives and evocative experiences. Thus, the use of such words and phrases as tradition, technology, property, data, intelligence, 
progress, critical thinking, and so forth, carry forward the way of thinking of earlier times - as well as the silences and prejudices that were taken for granted.

Overcoming this general lack of historical perspective suggests one of the ways educational reformers can foster ecological intelligence. Students need to be encouraged to examine the history of key words in the modern vocabulary that are contributing to undermining the intergenerational knowledge of the community, to the colonization of other cultures, and that lead to behaviors that further degrade the environment. For example, they need to consider the cultural context that influenced John Locke's analogies for understanding the right of individuals to own property, the early cultural basis for thinking of technology as a neutral tool, as well as the basis for thinking of traditions as obstructing progress and rational thought.

Ecological intelligence involves escaping from the linguistic colonization of the present by the past. An especially critical example of when ecological intelligence needs to be encouraged is when professors, political elites, and demagogues in the United States refer to the economic polities of Milton Friedman, Ronald Reagan, and George W. Bush as conservative. These promoters of capitalism, the globalization of free markets, and undermining of Constitutional protections should be more accurately described as marketliberals. To reiterate a key point: words have a history, and the word conservative, when used as a category of political theory in the West, can be traced back to Edmund Burke who warned about the danger of basing changes on abstract (and supposedly universal) ideas, to Michael Oakeshott who explained how the rationalization of the work place de-skills the worker, to the authors of The Federalist Papers who justified the separation of powers, to contemporary environmental thinkers such as Aldo Leopold, Wendell Berry, and Vandana Shiva. The word conservative carries forward many problematic interpretations of what should be conserved, such as states' rights and prejudicial traditions. The important point, however, is that the genealogy of political metaphors such as conservatism, liberalism, libertarianism, socialism, marxism, as well as the root metaphors that frame their respective agendas and silences, need to be examined in terms of their hidden forms of colonization. Given the threat in the United States to our civil liberties, including such long-standing traditions as habeas corpus, the viability of local markets and democratic practices, and to the selfrenewing capacity of natural systems, it is important to think ecologically about how to rectify the use of our political vocabulary that may otherwise lead people to equate the political slippery slope leading to the further enclosure of the local cultural commons with modern progress and development. What Naomi Klein documents in her recent book, The Shock Doctrine: The Rise of Disaster Capitalism (2007,) is a powerful example of how modern political metaphors hide the process of economic and cultural colonization. Ecological intelligence avoids accepting the authority of abstract words and theories by focusing on the how the consequences of policies effect the prospects of the other participants in the larger cultural ecology — as well as on the fate of the natural systems. How fostering ecological intelligence leads to revitalizing the local cultural commons: To reiterate, the way we unknowingly accept basing relationships and values on the meaning of words that were framed by analogs selected hundreds of years ago becomes especially critical to whether we move to a post-industrial form of 
consciousness and community. Substituting the phrase "cultural and environmental commons" for what most people associate with the word community will help in making this transition. Even in its most positive use, the word community is too limited to convey the complexity of the cultural and natural ecologies that we dependent upon. Stripped down to the simplest explanation, the cultural commons represents the intergenerational knowledge, skills, and mentoring relationships that enable members to be more self-reliant in the areas of food, healing, creative arts, craft skills, narratives, ceremonies, civil liberties, and other aspects of daily life that are less dependent upon consumerism and participation in a money economy. Basically, it encompasses what is shared in common, which may also include traditions of exploitation and prejudice. The word commons is now being used to refer to the cyber-commons, and its history in understanding the environment as a commons can be traced back to Roman law. The intergenerational knowledge and skills now being widely sharedranging from how to grow, prepare, and share a meal, how to discover talents and skills in a wide range of the arts, to the local efforts to make political decisions that protect the local cultural and environmental commons from being integrated into the supposedly free-market economy-have profoundly different consequences than what is experienced in a consumer dependent lifestyle. Revitalizing the cultural commons enables people to be less dependent upon a money economy that too often exploits the most vulnerable people as well as the environment that future generations will depend upon. The intergenerational knowledge and skills that represent alternatives to the industrial mode of production and consumption also have a smaller carbon and toxic ecological footprint. Furthermore, strengthening of the local cultural commons leads to developing the skills and relationships that are the basis of mutual support. In short, these life sustaining forms of ecological intelligence will vary from culture to culture and from bioregion to bioregion. And like traditions, such as the slow food movement, that are carried forward by mentors, the cultural and environmental commons will continue to exist along with a more selective dependence upon modern technologies. The challenge for educators, which is being made more daunting by the ideology that justifies greater reliance upon computer mediated learning, is to help students become aware of the forms of knowledge that take account of the limits and possibilities of the local bioregion, as well as patterns of mutual support that are essential to moving into the postindustrial era that we must enter if we are to avoid total ecological collapse.

The revitalization of local cultural commons across North America, and in Third World cultures that are questioning the western model of development, involve mutually supportive intergenerationally connected relationships. These relationships, if examined in terms of specific activities and skill development, are not framed in terms of fostering more "individual self-direction," "independence," and "ongoing questioning and revising." These words and phrases are based on the same deep cultural assumptions that lead to the kind of individualism required by the industrial/consumer-oriented culture. As these words and phrases have a special standing in the thinking of both market and social justice liberals, it is important to clarify how metaphors that are often associated with progress in achieving fuller individual lives may actually support the forces that lead to a consumer-dependent lifestyle. In Rebels Against the 
Future (1995), Kirkpatrick Sale notes that "it was the task of industrial society to destroy all...that 'community' implies - self-sufficiency, mutual aid, morality in the market place, stubborn tradition, regulation by custom, organic knowledge instead of mechanistic science..." (p. 38). He goes on to identify the connection that is often overlooked by educational reformers who emphasize the importance of individual emancipation: namely, that all the local cultural commons "practices that kept the individual from being a consumer had to be done away with so that the cogs and wheels of an unfettered machine called 'the economy' could operate without interference..." (Ibid.). In short, the industrial/consumeroriented culture requires the further enclosure of the cultural commons and an educational system that hides the dynamics of how language, in carrying forward the analogs settled upon by earlier culturally specific thinkers, is part of a colonizing process. The linguistic tradition of reproducing the conceptual errors of the past (in this case, the analogs settled upon by Enlightenment thinkers) can still be seen in how much of our thinking represents "traditions" as obstacles to progress and individual self-discovery. However, when we consider the traditions of organic gardening, of craft skills and knowledge, of the creative arts, of local decision making about how to protect civil liberties and the viability of the environmental commons, we find the traditions that we re-enact and modify in daily life are not impediments to progress. The experientially-grounded nature of ecological intelligence does not require treating progress as in opposition to traditions -and the students' discovery of interests and development of talents as being undermined by the forms of intergenerational knowledge and skills that are the community-basis of mutual support.

If we consider most learning relationships, without succumbing to the meaning of words dictated by the ideology of various expressions of liberal/progressive thinking that have given us a mixed legacy of social justice achievements and the industrial/consumer-dependent culture, we will find that traditions, intergenerational knowledge and skills, awareness of relationships and patterns of mutual support, the use of language that takes account of context and tacit understandings, and moments of dialogue, are integral to the students' pursuit of interests, questions, and desire to achieve at a deeper level of accomplishment. We need to continually think against the grain of today's formulaic thinking by keeping in mind that the western theorists who identified the analogs that now frame the meaning of such words as progress, individualism, freedom, emancipation, and so forth, were not aware of ecological limits. Their analogs reflected the advanced thinking of their era. Like the Roman god Janus, their vocabulary enabled us to make important gains in the area of correcting social injustices and in establishing a framework for civil liberties. Now we need to revise this vocabulary in ways that are culturally and ecologically informed. These words can then take on the meanings that reinforce the exercise of ecological intelligence, which requires becoming more ethnographically informed about the differences between the cultural patterns that strengthen traditions of community mutual support and those that adversely impact the viability of natural systems. 


\section{References}

Bowers, C. A. (2008). Philosophy, Language, and the Titanic Mind-Set. Language and Ecology. 2(1), 1-16.

Bateson, G. (1972). Steps to an ecology of mind. New York: Ballantine Books.

Goleman, D. (2009). Ecological intelligence: How knowing the hidden impacts of what we buy can change everything. New York: Broadway Books.

Klein, N. (2007). The shock doctrine: The rise of disaster capitalism. New York: Metropolitan Books/Henry Holt.

Sale, K. (1995). Rebels against the future: The luddites and their war on the Industrial Revolution. Reading, MA: Addison-Wesley.

C. A. (Chet) Bowers holds a PhD from the University of California in educational studies (with an emphasis on education and social thought), has taught at the University of Oregon and Portland State University, and was granted emeritus status in 1998. Currently, he is Courtesy Professor of Environmental Studies at the University of Oregon. 